\title{
Efficient Method of Transporting Coconut (Cocos nucifera L.) Zygotic Embryos for Cryopreservation of Plumules by Encapsulation/Dehydration
}

\author{
H D D Bandupriya ${ }^{1 *}$, S C Fernando ${ }^{1,2}$, J-L Verdeil $^{3}$, and B Malaurie ${ }^{4}$
}

\begin{abstract}
Coconut is both socially and economically important crop in tropical and subtropical countries, thus the conservation of existing diversity of its germplasm is vital to maintain biodiversity, sustain crop production and utilisation of germplasm for crop improvement strategies. The recalcitrant storage behavior and large size of the coconut seed make it impossible to use as a germplasm storage material. Cryopreservation is an ideal means of long-term storage of germplasm which offers long-term storage capability with minimal storage space and maintenance requirements. The coconut embryo has been now adapted by various researchers for the purpose of germplasm exchange and it is now being routinely applied in germplasm collection and exchange activities with sufficient germination rates. The aim of the present study was to determine the effect of different coconut embryo transport/ storage methods [as solid endosperm plugs under cold temperature, embryos cultured in Solidified Agar Medium (SAM) or $\mathrm{KCl}$ solution under room temperature] on cryopreservation of plumules using encapsulation/dehydration method. The results revealed that plumules excised from embryos transported/ stored in SAM and pretreated with $1.0 \mathrm{M}$ sucrose could be cryopreserved with $71.8 \%$ survival and $56 \%$ recovery rates. The survival and recovery could be further increased up to $77.5 \%$ and $65 \%$ respectively by supplementation of $1.0 \mathrm{M}$ sucrose with $20 \mu \mathrm{M}$ ABA.
\end{abstract}

Keywords: Coconut, cryopreservation, solidified agar medium, sucrose, ABA

${ }^{1}$ Coconut Research Institute, Lunuwila, Sri Lanka.

Email:dbandupriya@yahoo.com; Tel: +94312262003; Fax: +94312257391

${ }^{2}$ School of Botany, University of Melbourne, Victoria 3010, Australia.

${ }^{3}$ CIRAD, UMR AGAP, 34398 Montpellier Cedex 5, France.

${ }^{4}$ IRD, UMR DIADE, BP 64501, 34394 Montpellier Cedex 5, France. 


\section{Introduction}

Coconut is both socially and economically important crop in tropical and subtropical countries, thus the conservation of existing diversity of its germplasm is vital to maintain biodiversity, sustain crop production and utilisation of germplasm for crop improvement strategies.The recalcitrant storage behavior and large size (Chin and Pritchard, 1988) of the coconut seed make it impossible to use as a germplasm storage material. Traditionally, coconut genetic resources are preserved as whole plants in field gene banks. These field gene banks in different countries are comprised of a total of 1416 coconut accessions (Batugal, 2005). However, conservation in the field gene banks is subjected to risks of losses caused by biological and climatic hazards. The most recent example is the threat of the deadly disease Bogia Coconut Syndrome on the survival of the international collection of the South Pacific's coconut accessions, held at a field gene bank in Papua New Guinea (http://www.nature.com/ news/south-pacific-coconut-gene-bank-underthreat-1.11792). In addition, field gene banks require huge land areas and routine maintenance is very expensive. Cryopreservation is an ideal means of long-term storage of germplasm which offers long-term storage capability with minimal storage space and maintenance requirements. This method enables maximum stability of phenotypic and genotypic characteristics of stored germplasm (Engelmann, 1997). It also provides the option for long-term backup of germplasm collections that might be at risk.

Bajaj in 1984 reported the earliest attempt on the cryopreservation of coconut using whole zygotic embryo. Germination of a single embryo after freezing was reported by using DMSO and slow freezing in a classical protocol (Chin et al., 1989). Successful cryopreservation of coconut embryos from immature nuts (7-8 months after pollination) and mature nuts has been reported (Assy-Bah and Engelmann, 1992a, b). Inadequate recovery conditions led to the low recovery of plantlets in spite of high survival rates obtained after cryopreservation. Coconut plumule (embryo meristem and first leaves), which is known to be free of viral diseases, appears to be an interesting starting material for cryopreservation (Malaurie et al., 2002) and has been conserved using encapsulation/dehydration method. Encapsulation-dehydration, a vitrification-based cryopreservation procedure is gaining importance and has greater potential for broad applicability. In this method, cell water is removed through osmotic and evaporative dehydration that increases cell viscosity to a critical point at which water forms a meta-stable glass on exposure to ultralow temperatures. Pretreatment with sucrose $(0.5-1.5 \mathrm{M})$ and drying on silica gel are the most common ways of achieving osmotic and evaporative dehydration respectively (Padro et al., 2012; Sharaf et a.,l 2012). N'Nan et al., (2008) and Malaurie et al., (2002) have assessed the effect of different sucrose concentrations and dehydratyion regimes for coconut and achieved $40-70 \%$ survival after cryopreservation by encapsulation/ dehydration method. Apart from the embryo, pollen which is the other allowed material for coconut germplasm exchange has been checked for its viability at low and ultra low temperatures (Karun et al., 2006; Karun and Sajini, 2010).

Characteristics of coconut seed (bulky, heavy and recalcitrant) limited the collection of germplasm from some of the geographic areas. These limitations however had serious impact on genetic resource conservation as large amount of coconut genetic diversity is located in remote areas. International exchange of coconut germplasm has specific recommendations (Frison et al., 1993), where it has been established that movement of germplasm should be done only on the form of embryo culture or pollen (Diekmann, 1999; Hocher et al., 2004; Malaurie, 2001). The coconut embryo has been now adapted by various researchers for the purpose of germplasm exchange and it is now being routinely applied in germplasm collection and exchange activities (Engelmann, et al 2002). Even though this technique works well for some varieties, adjustments need to be done for certain varieties for large scale germplasm exchange activities. The simplest procedure of collecting embryos consists of collecting endosperm plugs together with the embryo and transport under 
aseptic cold conditions (Rillo and Paloma 1991). Other protocols (Assy-Bah et al., 1987; Karun, 2001) involve disinfection of embryos and in vitro inoculation of embryos in a growth medium. Method of transportation/ storage affects embryo quality which in turn plays a crucial role in success of cryopreservation. This is particularly important when considering international exchange of coconut germplasm for the establishment of multi-site International Coconut Genebanks (Batugal and Jayashree 2005).

Thus, the aim of the present study was to determine the effect of different coconut germplasm transport/storage methods on cryopreservation of plumules using encapsulation/dehydration method.

\section{Materials and methods}

\section{Plant material}

Mature nuts were obtained from 12 month old nuts of the variety Sri Lanka Tall. The nuts were collected from palms at Bandirippuwa Estate, Coconut Research Institute of Sri Lanka.

\section{Preparation of embryos for transportation/ storage}

Three different transport/store conditions were tested. In the first method solid endosperm plugs were extracted using a cock borer as described by Rillo and Paloma (1991), washed in tap water and in $95 \%$ ethanol quickly to remove the fats, and then disinfected with $100 \%$ commercial bleach (5.25\% active chlorine) for 20minutes. The plugs are then washed three times with sterile water and packed in sterile polypropylene bags and refrigerated for 10 days (Figure 1a). In the second and third methods, dissected coconut embryos were disinfected with $20 \%$ commercial bleach for 5 minutes, rinsed with sterile water for three times, cultured in SAM [ $0.45 \%(\mathrm{w} / \mathrm{v})$, Sigma] and $\mathrm{KCl}$ solution $(16.2 \mathrm{~g} / \mathrm{L})$ respectively (Figure $1 \mathrm{~b}$ and $\mathrm{c}$ respectively) and then stored at $27^{\circ} \mathrm{C}$ in the dark for 10 days. After the storage period, the endosperm plugs were re-sterilized in $100 \%$ commercial bleach for 20 minutes and embryos were dissected inside a laminar air flow cabinet (Figure 1d). The embryos dissected from endosperm plugs and the embryos stored in $\mathrm{SAM}$ and $\mathrm{KCl}$ (Figure 2e) were then disinfected with 20\% commercial bleach for 5 minutes and washed with sterile water for 5 times before dissecting plumules. Plumules were dissected as described by Chan et al., (1998) using stereo binocular under laminar flow conditions (Figure1f).

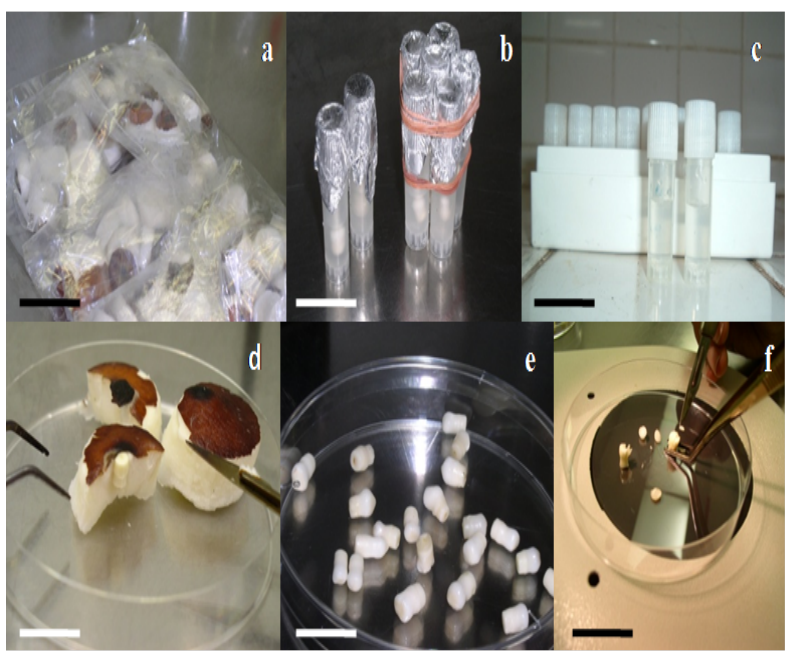

Figure 1. Different embryo transport/store methods and subsequent steps during plumule isolation. a. The endosperm plugs packed in sterile polypropylene bags. b. Embryos cultured in SAM. c. Embryos cultured in $\mathrm{KCl}$ solution. $\mathrm{d}$. Dissecting of embryos from endosperm plug. e. Mature embryos. f. Dissecting plumule. Scale Bars $6 \mathrm{~cm}$ in a, $2 \mathrm{~cm}$ in b and c, $3 \mathrm{~cm}$ in $\mathrm{d}, 1.5 \mathrm{~cm}$ in $\mathrm{e}, 2 \mathrm{~cm}$ in $\mathrm{f}$.

\section{Encapsulation / dehydration and cryopreservation}

Dissected plumules were precultured on solid Eeuwens $\mathrm{Y}_{3}$ growth medium (Eeuwens, 1976) for 4-7 days in order to screen the contaminated explants. The plumules were encapsulated in alginate beads composed of 3\% $(\mathrm{w} / \mathrm{v})$ low viscosity alginic acid (Sigma Chemical Co. USA) in calcium free liquid $\mathrm{Y}_{3}$ medium ( $\mathrm{pH}$ 5.8) and allowed to polymerize for $45 \mathrm{~min}$ in liquid $\mathrm{Y}_{3}$ medium with $100 \mathrm{mM} \mathrm{CaCl} 2$ and $0.15 \mathrm{M}$ sucrose. Beads were then blotted dry on sterile filter papers to remove surface 
moisture. Encapsulated plumules were then subjected to pretreatment in cryoprotective medium (sucrose/ sucrose+ABA). Groups of 20 beads were put in each $125 \mathrm{~mL}$ Erlenmeyer flask containing $30 \mathrm{~mL}$ cryoprotective medium and shaken on a rotary shaker set at 90 to $100 \mathrm{rpm}$, at $27 \pm 1^{\circ} \mathrm{C}$ in the dark for 3 days. The beads were rapidly surface dried by blotting with sterile filter papers. Dehydration of beads (batches of 20) was carried out for $16 \mathrm{~h}$ inside glass jars by placing on top of $40 \mathrm{~g}$ dried silica gel separated by a filter paper. Half of the dehydrated beads were transferred to $2 \mathrm{~mL}$ cryotubes and directly plunged in to liquid nitrogen at least for $2 \mathrm{~h}$. The other half of the beads was cultured in the solid $\mathrm{Y}_{3}$ recovery medium.

\section{Pretreatment in sucrose}

Two sucrose concentrations were tested for the pretreatment step for each of the embryo transport/storage conditions. Encapsulated plumules which were dissected from the embryos (Sri Lanka Tall variety) stored under three conditions were pretreated in the standard $\mathrm{Y}_{3}$ medium (Eeuwens 1976) supplemented with either $0.75 \mathrm{M}$ or $1.0 \mathrm{M}$ sucrose.

\section{Pretreatment in ABA}

Incorporation of abscisic acid in to the pretreatment medium was tested for two transport conditions. Plumules were dissected from embryos stored in SAM or in $\mathrm{KCl}$ solution. Encapsulated plumules were pretreated in the liquid Eeuwens $\mathrm{Y}_{3}$ medium, enriched with $1.0 \mathrm{M}$ sucrose alone or in combination with three ABA concentrations $(10,20$ and $40 \mu \mathrm{M})$.

\section{In vitro culture and assessment of survival and recovery}

\footnotetext{
Alginate beads containing plumules of control treatments (pretreated with cryoprotectant only or pretreated and dehydrated in silica gel and not cryopreserved) were directly cultured in $24 \times 150 \mathrm{~mm}$ test tubes containing 20 $\mathrm{mL}$ Eeuwens medium (Eeuwens, 1976) with modifications (Sandoval et al., 2003) whereas cryopreserved beads were cultured after thawing inside a $40^{\circ} \mathrm{C}$ water bath for $3 \mathrm{~min}$. The medium was supplemented with $0.12 \mathrm{M}$ sucrose and the $\mathrm{pH}$ was adjusted to 5.0 before adding charcoal.
}

The medium was solidified with $4 \mathrm{~g} / \mathrm{L}$ Gelrite. Cultures were kept in the dark at $27 \pm 1{ }^{\circ} \mathrm{C}$ until first few leaves emerged and then maintained in $12 \mathrm{~h}$ light.

The survival was assessed as the percentage of plumules manifesting new tissue growth (indicated by any sign of growth such as swelling, development of new leaf primordia and/or callus formation). Here, survival was chosen as a more sensitive indicator in the protocols tested in addition to the recovery of plumules and assessed after 2 months of in vitro culture. The recovery of plumules (indicated by the ability of plumules to grow in to plantlets) following desiccation alone or desiccation and freezing was assessed after 6 months in culture.

\section{Statistical analysis}

The experiments were arranged in a complete randomized design with two to three replicates of 10 plumules per treatment. Contaminated explants were eliminated before collecting data. Data was subjected to Analysis of Variance and Fisher's Lest-Significant test using GenStat 10.1 software.

\section{Results}

\section{Combined effect of embryo transport/store conditions and sucrose pretreatment}

In this experiment, the effect of three different embryo transport/store conditions were tested on cryopreservation of coconut plumules. As sucrose has been reported to be an effective cryoprotectant for coconut plumules (N'Nan et al., 2008), studies were carried out using two different sucrose concentrations which have shown positive effects on coconut plumule cryopreservation.

\section{Survival of plumules}

Encapsulated plumules (without any of the treatments) did not show any difference in survival and re-growth in comparison with uncoated controls (data not shown). The survival of encapsulated plumules treated with cryopretectant but not dehydrated in silica gel, and not frozen plumules (which were not stored in liquid $\mathrm{N}_{2}$ ) was always over $95 \%$ for all transport methods (Table 1). There was no 
Table 1. Survival percentages of non-cryopreserved plumules as influenced by different transport methods

\begin{tabular}{l|lllll}
\hline $\begin{array}{l}\text { Sucrose } \\
\text { concentration }\end{array}$ & & \multicolumn{2}{|c}{$\mathbf{0 . 7 5 M}$} & \multicolumn{2}{c}{ 1.0M } \\
\hline Dehydration & & No & Yes & No & Yes \\
& & & & & \\
& Endosperm plugs & 95.5 & 32.5 & 100.0 & 56.9 \\
Transport method & SAM & 100.0 & 72.2 & 100.0 & 100.0 \\
& KCl solution & 100.0 & 54.8 & 100.0 & 30.6 \\
\hline
\end{tabular}

Table 2. Survival percentages of cryopreserved plumules as influenced by different transport methods

\begin{tabular}{l|lcccc}
\hline $\begin{array}{l}\text { Sucrose } \\
\text { concentration }\end{array}$ & & & $\mathbf{0 . 7 5 M}$ & & $\mathbf{1 . 0 M}$ \\
\hline Dehydration & & No & Yes & No & Yes \\
& & & & & \\
& Endosperm plugs & 25.0 & 42.6 & 5.6 & 34.7 \\
Transport method & SAM & 21.1 & 46.4 & 0.0 & 71.8 \\
& KCl solution & 12.5 & 63.5 & 0.0 & 12.5 \\
\hline
\end{tabular}

Table 3. Recovery percentages of non-cryopreserved plumules as influenced by different transport methods

\begin{tabular}{l|lllll}
\hline $\begin{array}{l}\text { Sucrose } \\
\text { concentration }\end{array}$ & & & $\mathbf{0 . 7 5 M}$ & \multicolumn{2}{c}{$\mathbf{1 . 0 M}$} \\
\hline Dehydration & & No & Yes & No & Yes \\
& & & & & \\
& Endosperm plugs & 95.5 & 0 & 100.0 & 27.5 \\
Transport method & SAM & 100.0 & 27.8 & 95.8 & 80.0 \\
& KCl solution & 100.0 & 25.4 & 100.0 & 22.2 \\
\hline
\end{tabular}

Table 4. Recovery percentages of cryopreserved plumules as influenced by different transport methods

\begin{tabular}{l|lllll}
\hline $\begin{array}{l}\text { Sucrose } \\
\text { concentration }\end{array}$ & & & $\mathbf{0 . 7 5 M}$ & & $\mathbf{1 . 0 M}$ \\
\hline Dehydration & & No & Yes & No & Yes \\
& & & & & \\
& Endosperm plugs & 0.0 & 4.5 & 0.0 & 5.6 \\
Transport method & SAM & 0.0 & 18.2 & 0.0 & 56.8 \\
& KCl solution & 0.0 & 19.8 & 0.0 & 0.0 \\
\hline
\end{tabular}


significant difference in plumule survival following the two concentrations of sucrose application $(\mathrm{p}=0.345)$. However, plumule survival after dehydration in silica gel significantly $(\mathrm{p}=0.011)$ depended on embryo transport/ storage method and sucrose treatment; endosperm plugs $32.5 \%$ and $56.9 \%$, in $\mathrm{KCl}$ $54.8 \%$ and $30.6 \%$, in SAM $72.2 \%$ and $100 \%$.(values are for $0.75 \mathrm{M}$ and $1.0 \mathrm{M}$ sucrose respectively).

Encapsulated plumules pre-treated with sucrose, either in $0.75 \mathrm{M}$ or $1.0 \mathrm{M}$ showed very low survival rates ranging from 0 to $25.0 \%$, when they were cryopreserved directly without a dehydration step (Table 2). No significant difference $(\mathrm{P}=0.524)$ in survival was observed in dehydrated and cryopreserved plumules transported by three methods tested. But higher survival percentages were recorded in the plumules transported as embryos cultured in SAM $(71.8 \%$ in $1.0 \mathrm{M}$ sucrose) and $\mathrm{KCl}(63.5 \%$ in $0.75 \mathrm{M}$ sucrose). Sucrose concentration in the preculture medium did not affect significantly $(\mathrm{P}$ $=0.135$ ) on plumule survival.

\section{Recovery of plumules}

Plumules which were non-dehydrated and non-cryopreserved showed high recovery rates $(>95 \%)$ irrespective of the transport/store condition and the sucrose concentration (table 3 ). However, dehydration caused a decrease in recovery of plumules which was significantly different among plumules excised from embryos transported/ stored in different ways $(\mathrm{P}<0.001)$ (Table 3). None of the dehydrated plumules recovered when the embryos were transported as endosperm plugs and pretreated with $0.75 \mathrm{M}$ sucrose. The greatest recovery $(80 \%)$ was obtained when non cryopreserved plumules were excised from embryos transported in SAM and pretreated with $1.0 \mathrm{M}$ sucrose. Whereas, the recovery of unfrozen plumules of the two other transport conditions (plugs and $\mathrm{KCl}$ ) ranged only between $22.2 \%$ and $27.8 \%$, respectively (Table 3)

Rapid freezing of plumules without dehydration resulted almost complete inhibition of plant recovery in all treatments (Table 4). There was a significant interaction effect $(\mathrm{P}=$
0.019) of transport condition, sucrose concentration and dehydration. Although two sugar concentrations tested were able to protect a proportion of plumules from dehydration damage, only embryos which were transported in SAM and pretreated with $1.0 \mathrm{M}$ sucrose showed significantly high recovery $(56.8 \%)$ after cryo storage.

\section{Effect of $A B A$ in pretreatment medium}

In an attempt to improve the percentage recovery, encapsulated plumules were precultured in $1.0 \mathrm{M}$ liquid sucrose medium containing different ABA concentrations for three days prior to dehydration and freezing. Two transport/store conditions SAM and $\mathrm{KCl}$ were tested. The plumules transported/stored as embryos cultured on SAM medium showed higher survival rates $(58.8 \%$ and $77.5 \%$ in $10 \%$ and $20 \%$ ABA respectively) after dehydration and cryopreservation compared to the plumules transported/stored as embryos in $\mathrm{KCl}$ (Table 5). Maximum survival rate of the plumules transported in $\mathrm{KCl}$ was recorded as $41.2 \%$ when they were pre-treated in either 20 or $40 \mu \mathrm{M}$ ABA. In contrast, this is a remarkable increase of survival after cryopreservation when compared to the survival $(12.5 \%$; Table 2) obtained for plumules transported in $\mathrm{KCl}$ and pre-treated in $1.0 \mathrm{M}$ sucrose devoid of ABA. A very low survival ranging from $0.0 \%$ to $18.8 \%$ was recorded after cryo storage (Table 5) of non dehydrated plumules in both transport conditions but none of them developed in to plantlets later on (Table 6). Regardless of the ABA concentration embryo transport method had a significant effect on survival $(\mathrm{P}=0.01)$ and recovery of cryopreserved plumules. After freezing, the best regrowth of plumules was observed for plumules pretreated in $10 \mu \mathrm{M}$ ABA $(40.0 \%)$ and $20 \mu \mathrm{M}$ ABA (65.0\%) when embryos were stored in SAM (Table 6).

\section{Recovery and plant regeneration}

Surviving plumules resumed growth at variable pace but started after about four weeks at the earliest (Figure 2a). Leafy shoots mostly without roots were recovered after freezing (Figure $2 \mathrm{~b}$ and $\mathrm{d}$ ). Plumules that turned brown after cryopreservation did not recover in to 
Table 5. Effect of ABA concentration and transport/store condition on survival percentages of encapsulated cryopreserved plumules of coconut

\begin{tabular}{l|lllll}
\hline Embryo transport method & \multicolumn{3}{c}{$\boldsymbol{S A M}$} & \multicolumn{3}{c}{$\boldsymbol{K \boldsymbol { l }}$} \\
\hline Dehydration & & No & Yes & No & Yes \\
& & & & & \\
& 0 & 12.5 & 52.5 & 0.0 & 16.2 \\
ABA concentration $(\mu \mathrm{M})$ & 10.0 & 0.0 & 58.8 & 0.0 & 21.2 \\
& 20.0 & 12.5 & 77.5 & 5.0 & 41.2 \\
& 40.0 & 18.8 & 50.0 & 6.2 & 41.2 \\
\hline
\end{tabular}

Table 6. Effect of ABA concentration and transport/store condition on recovery percentages of encapsulated cryopreserved plumules of coconut

\begin{tabular}{l|lllll}
\hline Embryo transport method & \multicolumn{3}{c}{$\boldsymbol{S A \boldsymbol { C l }}$} \\
\hline Dehydration & & No & Yes & No & Yes \\
& & & & & \\
& 0 & 0.0 & 6.2 & 0.0 & 6.2 \\
ABA concentration $(\mu \mathrm{M})$ & 10.0 & 0.0 & 40.0 & 0.0 & 11.2 \\
& 20.0 & 0.0 & 65.0 & 0.0 & 18.8 \\
& 40.0 & 0.0 & 35.0 & 0.0 & 0.0 \\
\hline
\end{tabular}
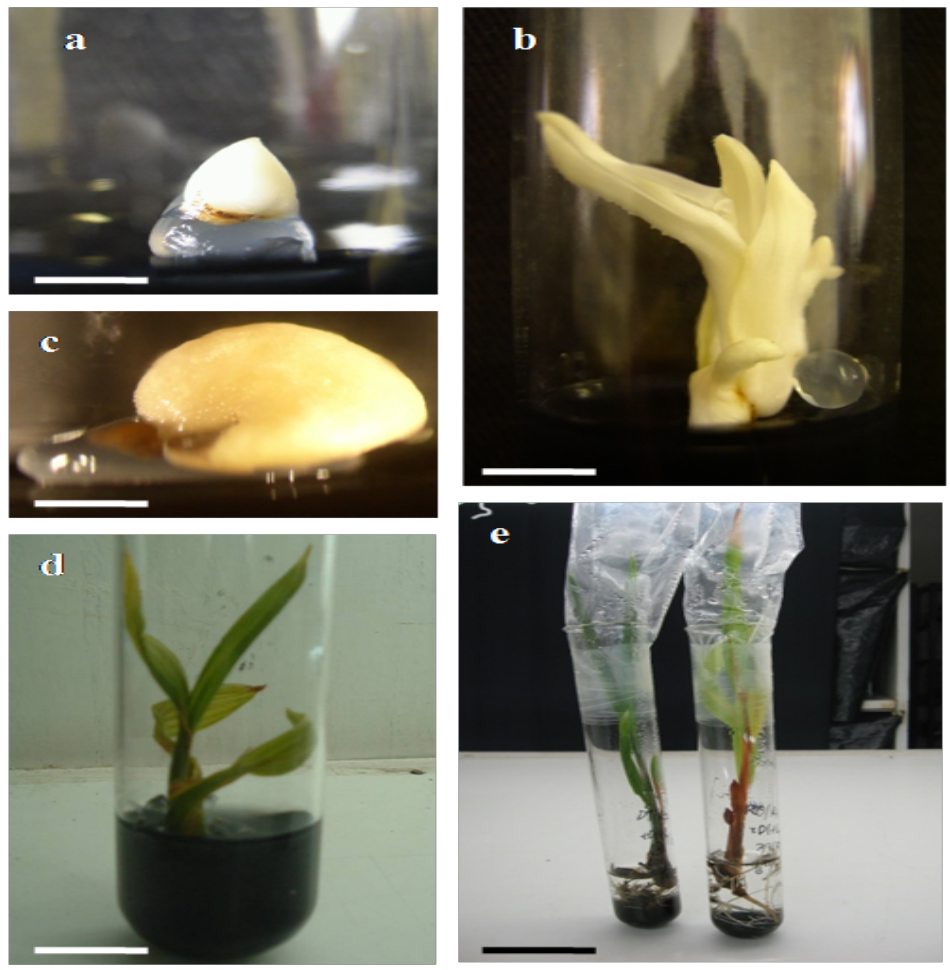

Figure 2. Different development stages of plumules after cryopreservation. a. Re-growth starting after four weeks after cryopreservation. b. Germinating plumule in the recovery medium. c. Initiation of callus like growth after cryopreservation. d. Complete shoot developed after cryo storage. e. Complete/rooted plantlets developed from recovered shoots. Scale Bars $5 \mathrm{~mm}$ in a, $1 \mathrm{~cm}$ in b, $5 \mathrm{~mm}$ in c, $1.5 \mathrm{~cm}$ in $\mathrm{d}, 5 \mathrm{~cm}$ in e. 
plantlets. Very rarely plumules exhibited survival by initiating callus like growth (Figure 2c) with no further development. Root development of the surviving shoots in liquid Y3 medium was achieved by giving a IAA plus (200 $\mu \mathrm{M})$ for two days (figure 2e). Majority of recovered plantlets were contaminated during sub-culturing and a very few plants were acclimatized in soil.

\section{Discussion}

The potential of exchanging and storing healthy germplasm is vital for the conservation and use of genetic resources for coconut breeding programmes. Coconut zygotic embryos are now routinely being transported between numerous laboratories to support germplasm collection and exchange activities. (Batugal and Engelmann 1998; Engelmann et al., 2002) However, even though coconut embryos are being transported in different conditions and they ensure high rates of embryo germination (N'Nan et al., 2012; Sisunandar et al., 2010) these germplasm exchange procedures have not been evaluated for the purpose of storage of coconut germplasm for long term conservation. In this study, coconut plumules originally transported/stored in different conditions were successfully cryopreserved using encapsulation/ dehydration.

It has been demonstrated that successful cryopreservation is achieved by avoiding the formation of intra cellular ice crystals which are formed during the freezing process causing lethal physical damage to tissues (Gale et al., 2007). Encapsulation/dehydration is an effective, widely using vitrification method for freezing shoot apices of different plant species from both temperate and tropical origin (Gonzalez-Arno and Engelmann 2006) since it is a simple and inexpensive method providing high level of genetic stability (Sakai et al., 1990; Khoddamzadedh et al., 2011).

In the encapsulation/dehydration method, tissues are dehydrated by evaporative dehydration (Shibli et al., 2001) to minimize the intra cellular water content. The exposure of tissues directly to dehydration step causes harmful effects due to osmotic stress (Touchell et al., 2002). Normally, preculture in sugars (Sharaf et al., 2012); mainly sucrose or other cryoprotectants such as sugar alcohols (Ford et al., 2000), glycerol (Rajasekaran, 1996) and DMSO (Reed, 1990) is used to increase the tolerance of tissues to dehydration before the immersion in liquid nitrogen. Sucrose concentrations ranging from $0.75 \mathrm{M}-1.0 \mathrm{M}$ are suitable for ensuring high survival rates after cryopreservation for crops such as mulberry, apple, grapevine and citrus (Paul et al., 2000; Wang et al., 2000; Wang et al., 2002; Padro et al., 2012;). There are reports of using sucrose as a cryoprotectant for the cryopreservation of plumule explants of coconut (Hornang et al., 2001; N'Nan et al., 2008). N'Nan and others reported $39 \%$ survival and $16 \%$ recovery of coconut plumules after cryo storage when the encapsulated plumules were pretreated with $0.75 \mathrm{M}$ sucrose (N'Nan et al., 2008). On the other hand, when the plumules were pretreated with $1.0 \mathrm{M}$ sucrose, the survival rate was approximately $34 \%$ and the recovery was $10 \%$. It is noted that the embryos used for the above experiments have been transported as endosperm plugs only. In this study we obtained similar results for the survival of plumules transported as endosperm plugs when precultured in the two sucrose concentrations $0.75 \mathrm{M}(42.6 \%)$ and 1.0 M (34.7\%). However, the positive effect of transporting embryos in SAM was observed by obtaining considerably higher survival rate $(71.8 \%)$ when cryoprotected in $1.0 \mathrm{M}$ sucrose. This was further confirmed by obtaining more than $56 \%$ recovered plantlets after cryopreservation when the plumules were transported in SAM. The results obtained are interesting as it is shown that the medium surrounding the coconut embryo (endosperm or the supplemented medium) can be replaced by agar alone without nutrition factors which ensure higher survival and recovery rates. These findings will permit convenient exchange of coconut embryos between laboratories and allow efficient germplasm distribution among the coconut growing countries.

The role of ABA in desiccation and freezing tolerance has been demonstrated not only in higher plants but also in lower plants 
such as bryophytes (Senaratna et al., 1989; Werner et al., 1991). Pretreatment with ABA has been shown to be effective for cryopreservation of several moss species (Pence, 1998). There are reports of successful plant material cryopreservation by incorporating ABA to the pretreatment medium (Kendall et al., 1993; Na and Kondo, 1996; Fang et al., 2004; Uchendu et al., 2011). A combination of ABA and sucrose pretreatments improved the survival of cryopreserved coconut plumules (Bandupriya et al., 2007). Addition of ABA to the pretreatment medium increased the recovery of cryopreserved plumules by recording 38\% (Malaurie et al., 2006) and 39\% (Bandupriya et al., 2007) recovery when compared to the recovery rates $(20 \%)$ obtained previously by N'Nan et al in 2008. However these experiments have been carried out by transporting embryos as endosperm plugs (Malaurie et al., 2006) or without applying any transport condition (Bandupriya et al., 2007). In this paper we describe significantly high $(65 \%)$ recovery of cryopreserved plumules which were initially transported/stored in SAM and when they were pretreated in $1.0 \mathrm{M}$ sucrose supplemented with $20 \mu \mathrm{M}$ ABA. These findings show that ABA addition to the pretreatment medium improves the recovery after cryopreservation significantly. Moreover it is shown that the effect of ABA has been elevated by the use of SAM as a transport support medium for the exchange of coconut embryos and reveals the importance of the selection of a correct transport conditioning of embryos prior to cryopreservation.

\section{Acknowledgments}

This research was supported by the Bureau des Resources Genetiques, Paris, France (BRG). The authors gratefully acknowledge the staff members of Lab Genetrop, IRD, France and Tissue Culture Division, CRI, Sri Lanka for their assistance in carrying out the experiments.

\section{References}

Assy-Bah, B., Durand-Gasselin, T. and Pannetier C. (1987) Use of zygotic embryo culture to collect germplasm of coconut (Cocos nucifera L.). FAO/IBPGR Plant Genetic Resource Newsletter 71: 4-10.
Assy-Bah, B. and Engelmann, F. (1992 a) Cryopreservation of immature embryos of coconut (Cocos nucifera L.). CryoLetters 13: 67-74.

Assy-Bah, B. and Engelmann, F. (1992 b) Cryopreservation of mature embryos of coconut (Cocos nucifera L.) and subsequent regeneration of plantlets. CryoLetters 13: 117-126.

Bajaj, Y.P.S. (1984) Induction of growth in frozen embryos of coconut and ovules of Citrus. Current Science 53:1215-1216.

Bandupriya, H.D.D., Fernando, S.C., Verdeil, JL. and Malaurie, B. (2007) Effect of Abscisic acid on survival and recovery of cryopreserved plumule explants of coconut (Cocos nucifera L.). Cocos 18: 45-51.

Batugal, P. (2005) The International Coconut Genetic Resources Network (COGENT); its history and achievements. Coconut genetic resources (eds. P. Batugal, V. Ramanatha Rao, J. Oliver), pp 482-499. IPGRI-APO (Bioversity International), Serdang, Selangor, Malaysia.

Batugal, P. and Jayashree, K. (2005) COGENT's multi-site International Coconut Genebank. Coconut genetic resources (eds. P. Batugal, V. Ramanatha Rao, J. Oliver), pp 106-114. IPGRI-APO (Bioversity International), Serdang, Selangor, Malaysia.

Chan, J.L., Saenz, L., Talavera, C., Hornung, R., Robert, M. and Oropeza, C. (1998) Regeneration of coconut (Cocos nucifera L.) from plumule explants through somatic embryogenesis. Plant Cell Reports 17:515-521.

Chin, H.F. and Pritchard, H.W. (1988) Recalcitrant seeds, a status report. International Board for Plant Genetic Resources, Rome.

Chin, H.F., Krishnapillay, B. and Hor, Y.L. (1989) A note on the cryopreservation of coconut embryos from young coconuts (Cocos nucifera L. var. Mawa). Pertanika 12 (2):183-186. 
Diekmann, M. (1999) The use of biotechnology for the safe movement of coconut germplasm. Current Advances in Coconut Biotechnology (eds. C. Oropeza, JL.Verdeil, G.R. Ashburner, R. Cardena and J.M. Santamaria), pp 259. Kluwer Academic Publishers, Dordrecht, Netherlands.

Engelmann, F. (2002) Coconut. In vitro collecting techniques for germplasm conservation (eds. V.C. Penc, J.A. Sandoval, V.M.A.Villalobos and F. Engelmann), pp 68-71. IPGRI technical bulletin No 7 IPGRI, Rome.

Engelmann, F. (1997) In vitro conservation methods. Biotechnology and plant genetic resources: Conservation and use (eds. B.V. Ford-Lloyd, H.J. Newbury and J.A. Callow), pp119-162. CABI, UK.

Fang, J.Y., Wetten, A. and Hadley, P. (2004) Cryopreservation of cocoa (Theobroma cocoa L.) somatic embryos for long term germplasm storage. Plant Science 166:669-675.

Ford, C.S., Jones, N.B. and van Staden, J. (2000) Cryopreservation and plant regeneration from somatic embryos of Pinus patula. Plant Cell Reports 19: 610-615.

Frison, E.A., Putter, C.A.J. and Diekmann, M. (1993) FAO/IBPGR technical guidelines for the safe movement of coconut germplasm. Food and Agricultural Organization of the United Nations/International Board for Plant Genetic Resources, Rome.

Gale, S., John, A. and Benson, E.E. (2007) Cryopreservation of Picea sitchensis (Sitka spruce) embryogenic suspensor masses. CryoLetters 28:225-239.

Gonzalez-Arnao, M.T. and Engelmann, F. (2006) Cryopreservation of plant germplasm using the encapsulationdehydration technique: review and case study on sugarcane. CryoLetters 27(3):155-168.
Hocher, V., Verdeil, J-L. and Malaurie, B. (2004) Cocos nucifera, Coconut. Biotechnology of Fruit and Nut Crops (eds. R.E. Litz), pp 90-112. CABI Publishing Tropical Research and Education Center, University of Florida, USA.

Hornung, R., Domas, R. and Lynch, P.T. (2001) Cryopreservation of plumular explants of coconut (Cocos nucifera L.) to support programmes for mass clonal propagation through somatic embryogenesis. CryoLetters 22: 211-220.

Karun, A. (2001) Embryo culture protocol for collection and exchange of coconut germplasm. Indian Coconut Journal 31 (9): 17-18.

Karun, A., Sajini, K. K. S., Nair, M., Kumaran, P. M. and Samsudheen, K. (2006) Cryopreservation of coconut (Cocos nucifera L.) pollen. Journal of Plantation Crops 3: 568-571.

Karun, A. and Sajini, K. K. (2010) Cryopreservation of coconut zygotic embryos and pollen. Central Plantation Crops Research Institute, Kasaragod, India.

Kendall, E.J., Kartha, K.K., Qureshi, J.A. and Chermak, P. (1993) Cryopreservation of immature spring wheat zygotic embryos using an abscisic acid pretreatment. Plant Cell Reports 12 (2): 89-94.

Khoddamzadeh, A., Sinniah, U., Lynch, P., Abdul Kadir, M., Kadzimin, S. and Mahmood, M. (2011) Cryopreservation of protocorm-like bodies (PLBs) of Phalaenopsis bellina (Rchb.f.) christenson by encapsulation-dehydration. Plant Cell Tissue and Organ Culture 107 (3): 471481.

Malaurie, B. (2001) Medium and long term conservation and safe international exchange of germplasm from food and cash tropical crops. Acta Horticulturae 560: 69-77.

Malaurie, B., Bandupriya, H.D.D., Fernando, S.C. and Verdeil, J-L. (2006) Optimisation 
du procédé de cryoconservation de la plumule de cocotier. Les Actes du BRG 6: 449-468.

Malaurie, B., Borges, M. and N'Nan, O. (2002) Research of an optimal cryopreservation process using encapsulation/ osmoprotection/ dehydration and encapsulation/osmoprotection/vitrification techniques on caulinary meristems of coconut (Cocos nucifera L.). Burotrop Bulletin 20:16.

Moorhead, A. (2012) South Pacific coconut gene bank under threat. Available at http://www.nature.com/news/south-pacificcoconut-gene-bank-under-threat-1.11792, Accessed 10 January 2013.

$\mathrm{Na}$, H-Y. and Kondo, K. (1996) Cryopreservation of tissue-cultured shoot primordia from shoot apices of cultured protocorms in Vanda pumila following ABA preculture and desiccation. Plant Science 118 (2): 195-201.

N'Nan, O., Borges, M., Konan, J-L.K., Hocher, V., Verdeil, J.-L., Tregear, J., N'guetta, A.S.P., Engelmann, F. and Malaurie, B. (2012) A simple protocol for cryopreservation of zygotic embryos of ten accessions of coconut (Cocos nucifera $\mathrm{L}$.) In Vitro Cellular and Developmental Biology-Plant 48:160-166.

N'Nan, O., Hocher, V., Verdeil, J-L., Konan, JL., Ballo, K., Mondeil, F. and Malaurie, B. (2008) Cryopreservation by encapsulationdehydration of plumules of coconut (Cocos nucifera L.). CryoLetters 29 (4): 339-350.

Padro, M.D.A., Frattarelli, A., Sgueglia, A., Condello, E., Damiano, C. and Caboni, E. (2012) Cryopreservation of white mulberry (Morus alba L.) by encapsulation-dehydration and vitrification. Plant Cell Tissue and Organ Culture 108:167-172.

Paul, H., Daigny, G. and Sangwan-Noreel, B.S. (2000). Cryopreservation of apple (Malus $\mathrm{x}$ domestica Borkh.) shoot tips following encapsulation-dehydration or encapsulation-vitrification. Plant Cell Reports 19: 768-774.

Pence, V.C. (1998). Cryopreservation of bryophytes: The effects of abscisic acid and encapsulation dehydration. Bryologist 101: 278-281.

Rajasekaran, K. (1996) Regeneration of plants from cryopreserved embryogenic cell suspension and callus cultures of cotton (Gossypium hirsutum L.). Plant Cell Reports 15: 859-864.

Reed, B.M. (1990) Survival of in Vitro-grown apical meristems of Pyrus following Cryopreservation. HortScience 25: 111113.

Rillo, E.P. and Paloma, M.B.F. (1991) Storage and transport of zygotic embryos of Cocos nucifera L. for in vitro culture. FAO/IBPGR Plant Genet Resources Newsletter 86:1-4.

Sakai, A. and Engelmann, F. (2007). Vitrification, encapsulation-vitrification and droplet-vitrification: a review. CryoLetters 28:151-172.

Senaratna, T., McKersie, B.D. and Bowley, S.R. (1989) Desiccation tolerance of alfalfa (Medicago sativa L.) somatic embryos. Influence of abscisic acid, stress pretreatments and drying rates. Plant Science 65: 253-259.

Sharaf, S.A., Shibli, R.A., Kasrawi, M.A. and Baghdadi, S.H. (2012) Cryopreservation of wild Shih (Artemisia herba-alba Asso.) shoot-tips by encapsulation-dehydration and encapsulation-vitrification. Plant Cell Tissue and Organ Culture 108: 437-444.

Shibli, R.A., Haagenson, D., Cunningham, S., Berg, W. and Volenec, J. (2001) Cryopreservation of alfalfa (Medicago sativa L.) cells by encapsulationdehydration. Plant Cell Reports 20 (5): 445-450.

Sisunandar, Sopade, P.A., Samosir, Y.M.S., Rival, A. and Adkins, S.W. (2010) 
Dehydration improves cryopreservation of coconut (Cocos nucifera L.). Cryobiology 61:289-296.

Touchell, D.H., Chiang, V.L. and Tsai, C.J. (2002) Cryopreservation of embryogenic cultures of Picea mariana (black spruce) using vitrification. Plant Cell Reports 21: 118-124.

Uchendu, E.E., Brown, D.C.W. and Saxena, P.K. (2011) Cryopreservation of shoot tips and cotyledons of the North American ginseng (Panax Quinquefolius L.) CryoLetters 32(6): 463-472.

Wang, Q.C., Tanne, E., Arav, A. and Gafny, R. (2000) Cryopreservation of in vitro-grown shoot tips of grapevine by encapsulationdehydration. Plant Cell Tissue and Organ Culture 63: 41-46.

Wang, Q.C., Batuman, O., Li, P., Bar-Joseph, M. and Gafny, R. (2002) Cryopreservation of in vitro grown shoot tips of 'Troyer' citrange [Poncirus trifoliata Raf. $\times$ Citrus sinensis (L.) Osbeck.] by encapsulationdehydration. Plant Cell Reports 20: 901906.

Werner, O., Espin, R.M.R., Bopp, M. and Atzorn, R. (1991). Abscisic acid induced drought tolerance in Funaria hygrometrica Hedw. Planta 186: 99-103. 